Historic, Archive Document

Do not assume content reflects current scientific knowledge, policies, or practices. 



\title{
SOME PECAN NOTES
}

\author{
By̆ J. B. WIGITT, Ciniro, Gin. \\ (Reprint from The Progressive Farmer.)
}

INTEREST IN PECANS is growing. People are learning how good they are. Producers are also finding out how, by proper care, to grow them more profitably. With the ever widening market and more economical production the outlook for the producer is bright.

GROVES GOOD AND BAD.-There are individual trees and orchards of pecans which are highly profitable. The cause is not hard to find; it is GOOD CARE. There are others which financially are failures. The reason is apparent; they are NEGLECTED. The world has yet to discover a valuable product that will thrive under neglect. A poor pecan orchard is no more argument against the industry than is an abandoned cotton field a reason for growing no more cotton. You must first feed your trees if you want them to feed you.

GOOD CARE.-This means such attention as to cultivation and fertilizing as would be given any other orchard trees. It does not mean that animals or plow hands may run over and skin or break down the trees; nor that weeds and grass may take possession without serious damage. Briefly it requires that after the trees come into good bearing and in addition to summer and winter cover crops to be turned under, that 500 to 1000 pounds of high-grade guano should be annually applied per acre. For the first eight to ten years following setting, the grove should be planted to some well cultivated and fertilized crop. This crop should almost or quite pay for the care of the orchard. When the trees have come to the profitable bearing age (eight to ten years) then the plan outlined above should be followed. Pecans revel in a humus-filled soil that is liberally fed with fertilizer. 
PLANNING-EXECUTING.-A pecan orchard large or: small should be planned and cared for as carefully as any commercial enterprise. The best land should be selected; right varieties should be chosen; correct cultural methods should be followed. It costs no more to observe these points than it does to neglect them. But in the end the difference will be on the one hand an orchard that is a delight because of its beauty and profitableness, or on the other an eye-sore on account of its shabby appearance and unprofitableness.

FERTILIZING.-It requires brains mixed with industry to make a successful pecan orchard. No one expects to make a crop of corn or cotton or cabbage without using the right kind of land, nor without proper fertilizing, hoeing and plowing. Why should we look for a successful pecan orchard without the same care? Liberal fertilizing will pay good dividends. For the first few years this fertilizer may be applied about the tree in constant. ly increasing areas at the rate of about $11 / 2$ to 2 pounds for each year the tree has been set. When the trees come into good bearing it will be well to scatter the guano over the whole area. If stable manure is available, use it; there is nothing better. When the fertilizer is applied, don't let weeds and grass rob the trees of their food.

FERTILIZER FORMULAE.-Where guano is used, a high grade is better. A formula analyzing 8-5-3 or 9-6-4 (Phosphoric acid, ammonia and potash in order) is good for general conditions. This may be varied to suit special conditions or localities. An orchard in good bearing can profitably use from 500 to 1000 pounds per acre of the above formula, provided there is plenty of humus in the soil to help make it available.

SOILS.-Avoid the following: (1) Poor sandy soils. (2) Land where the soil has been washed off to the clay. (3) Poorly drained soils. As a rule any land that will yield good crops of corn or cotton will grow pecans successfully. Pecans love a soil that is well filled with vegetable matter. For this reason grow all the peas, velvet beans, or other leguminous crops you can, to be turned under to enrich the orchard.

THREE REQUISITES.-If success is to come to the pecan grower, there are certain precautions that must be observed: (1) Strong and vigorous budded trees should be set of such varieties as are adapted to the section where they are to be grown. Avoid stunted trees, for a runt in the nursery will remain a dwarf in the grove. (2) Set trees only on the best land. (3) Cultivate, fertilize and care for them in the best manner. These are the three most important requisites to successful pecan growing either on a small or a large scale. Observe them and you will not be disappointed. 
IF CONDITIONS ARISE which you do not understand, don't hesitate to consult your state experiment station or college of agriculture. It is their business to help you.

WHY FAILURES?-When po." land is used, or cultural methods are practiced which decrease rather than increase the humus content of the soil, a few indifferent crops of nuts may be gathered. But by the time the trees are ten to fifteen years old they almost cease their growth; leaves turn yellow, and nuts are very few. What is the trouble? Trees are being starved. No "bread has been cast upon the waters" and no returns have come in. Growers of farm crops know that we cannot continue to take from the soil without adding to it and not bring on soil depletion. The sooner pecan growers learn this, the better it will be for them.

PECANS VS. PEACHES.-Recently I asked a large peach and pecan grower of middle Georgia which of these he regarded the more profitable to grow for market. His reply was prompt: "Pecans." And yet the two may be successfully grown together in that to a great extent both require the same conditions of soil, culture, and fertilizing. Peaches should come into profitable bearing not later than the fourth year after setting. By the tenth or twelfth year when they have run their course, they may be removed, and the land given up to pecans which should by that time be in profitable bearing. Many are trying this combination.

EVERYONE HAVING LAND should be a grower of pecans. The small town or city lot may furnish room for one or more trees which in the end will produce sufficient nuts for home use. A few trees have often supplied the family wants, and the surplus has sold for enough to pay insurance and taxes. The small or large land owner should plant from one to five acres for each plow operated on the farm. This will add another money crop which is easily handled, and one that will very materially enhance the profits of the farm.

VALUE PER ACRE.-The value of a pecan orchard is hard to estimate. I know several which cannot be bought for $\$ 500.00$ to $\$ 1,000.00$ per acre, because they are yielding a net income of 8 per cent or more on this amount. I have one tree set in 1892, which for the last sixteen years has borne 4,066 pounds of nuts that at forty cents per pound (the average price at which they have sold) has yielded an average of $\$ 100.00$ per year. Is not this tree alone worth $\$ 1,000.00$ ?

PECAN GROWING is not a get rich quick scheme. It is a stable business enterprise which promises good profits to the careful grower. Once established a pecan orchard is good for a hundred years and more of profitable bearing. Trees in the native groves of the west have been cut, and by their rings show. 
that they are three hundred to four hundred years old. The pecan grower is not only doing a good work for himself tut he is planting for generations yet unborn.

\section{WHY SET PECANS?}

(1) They add a diversification to marketable crops, which will prove not only one of the most easily produced, but likely one of the most profitable grown on the farm.

(2) The pecan combines both beauty and utility. Its stately symmetrical shape adds beauty to any surroundings. There is no tree that combines both of these qualities to a higher degree.

(3) As a shade tree it is superior to the oak, sycamore, etc., in that it pays good rent for the ground it occupies.

(4) Pecans add to the permanent value of the land. If it is to be sold then it decidedly enhances the selling price.

(5) Ripening after most crops are harvested, they add to the length of the season for the profitable employment of farm labor.

(6) Unlike most fruits there is no necessary rush either in gathering or marketing the nuts. They do not suffer in quality if not gathered for weeks after they are ripe; and if stored in a cool place they do not deteriorate in quality if kept even for twelve months.

(7) Pecans are nature's own product, put up in air-tight and dust proof receptacles, and are unsurpassed for their flavor and healthfulness. As an economical and healthful food, adding variety to the dietary, they appeal to all who want to grow at home as much of the family supplies as possible.

(8) If correct methods are followed there is no doubt that pecans can be made highly profitable at the present level of prices. It is the opinion of our most experienced growers that the price can even be cut in half and still leave a profit for the grower.

(9) This generation nor the next will see an over-production of this best of all nuts. The present pecan crop of the United States if equally divided among all its people would give less than four ounces for each inhabitant. When we supply our own people, we still have the remainder of the world for a market.

The pecan appeals to the intelligent man or woman who wants to make the most of their opportunities. The indifferent and careless may as well continue to grow potatoes and cotton and razor-back hogs. 